\title{
WHY MY AVATAR LOOKS LIKE ME: \\ A STUDY ON IDENTITY IN DUNGEONS \& DRAGONS
}

\author{
by
}

\section{PAMELA LIVINGSTONE}

B.Comm, Ryerson University, 2014

\author{
A Major Research Paper \\ Presented to Ryerson University
}

In partial fulfillment of the

Requirements for the degree of

Master of Digital Media

In the Yeates School of Graduate Studies

Toronto, Ontario, Canada, 2015

(C) Pamela Livingstone, 2015 


\section{Author Declaration}

\section{AUTHOR'S DECLARATION FOR ELECTRONIC SUBMISSION OF A MRP}

I hereby declare that I am the sole author of this MRP. This is a true copy of the MRP, including any required final revisions.

I authorize Ryerson University to lend this MRP to other institutions or individuals for the purpose of scholarly research.

I further authorize Ryerson University to reproduce this MRP by photocopying or by other means, in total or in part, at the request of other institutions or individuals for the purpose of scholarly research.

I understand that my MRP may be made electronically available to the public.

Signed

Pamela Livingstone 


\begin{abstract}
The purpose of this paper is to study the effects of premade characters and visual aids on character connection in the analog role-playing game Dungeons \& Dragons. Four participants gathered together to play the game of Dungeons \& Dragons once a week for one month in May 2015. After the in-game research in-person interviews were conducted and the data was then coded in NVivo for major themes in relation to character connection. Research was also pulled from auto-ethnographic reflections to round out the data. The results of the data suggest that the participants felt that character customization, narrative, character backstory, as well as visuals played an important role in their ability to build a strong connection to their gaming avatar. Join the journey of four warriors building connection to their characters as they look to close the rift in the Shadowfell of the Keep.
\end{abstract}




\section{Acknowledgements}

I would like to thank my partner Jay for helping me get through my many years in University and who has been patient and supportive in the last few months of my degree. To my parents who helped me follow my dreams and who have constantly pushed me to be the best person I can be and do the best that I can do. My mom specifically for taking the time to edit all of my countless pages and papers because she loves me. My three brothers for always making me strive to do better and be better than them. And to my supervisor and long-time mentor Dr. Jaigris Hodson for helping me to find my true passion and for constantly guiding and supporting me and my ideas. 


\section{Table of Contents}

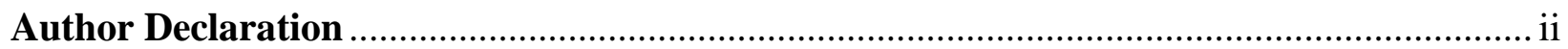

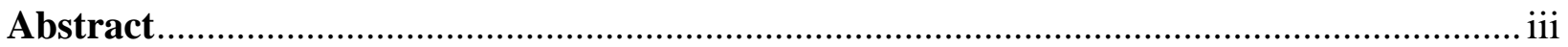

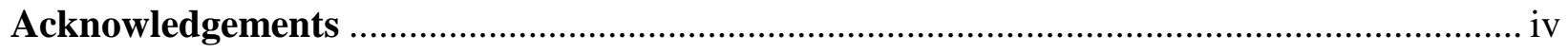

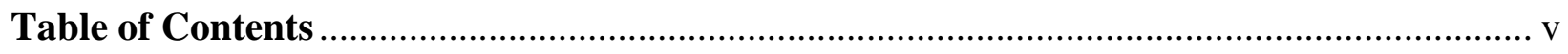

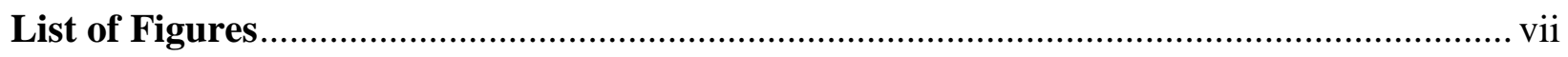

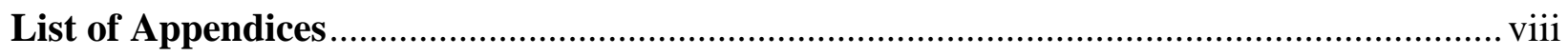

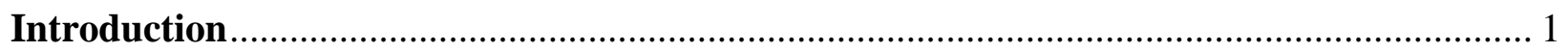

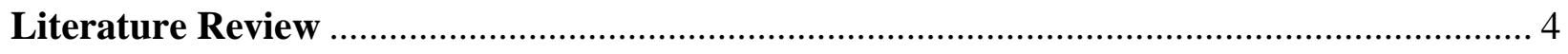

History of Role-playing Games ………………………….................................................. 4

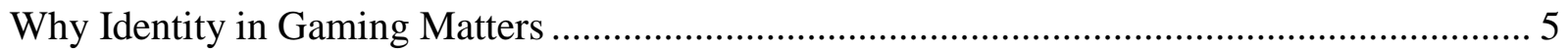

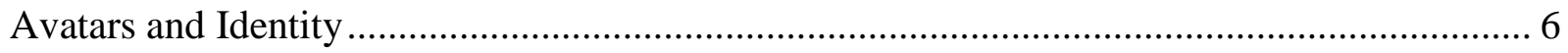

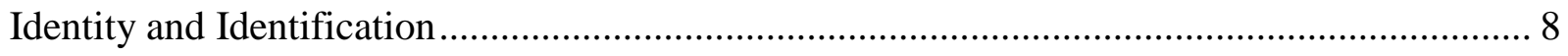

Customization within Avatar Identity .............................................................................. 11

Identity within Gaming Communities .............................................................................. 13

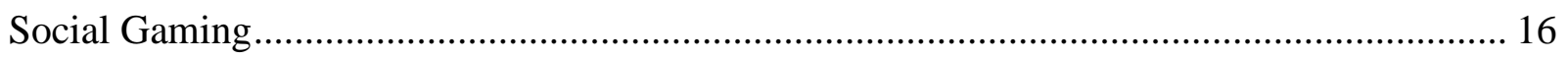

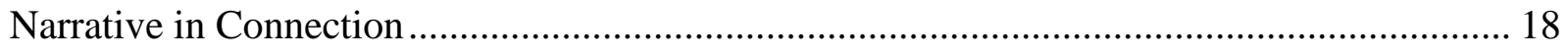

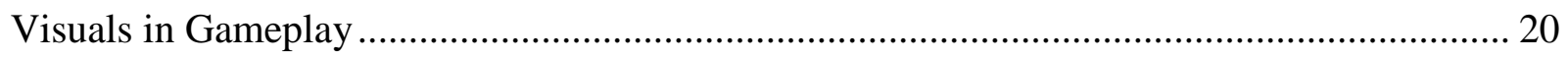

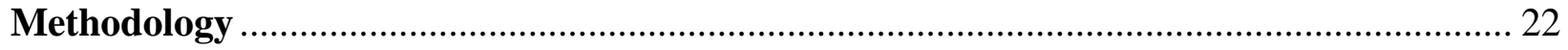

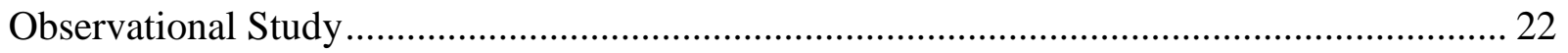

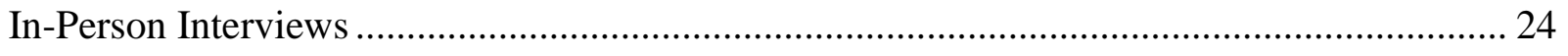

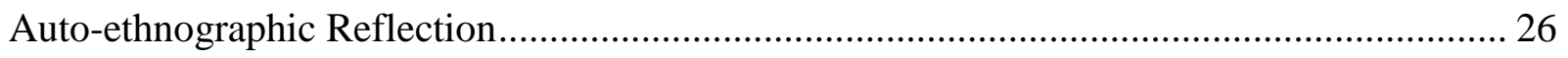


Study Design

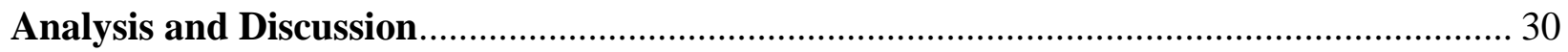

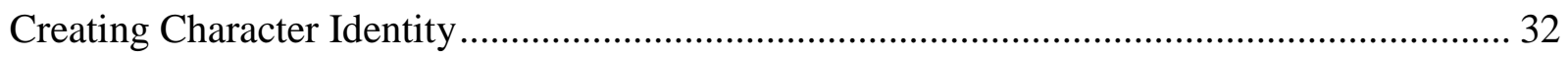

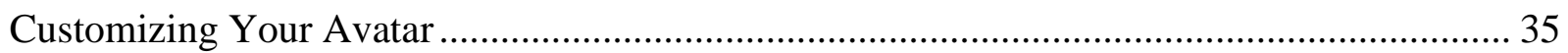

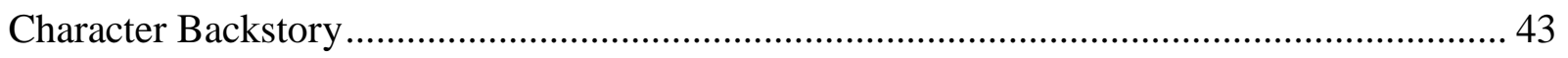

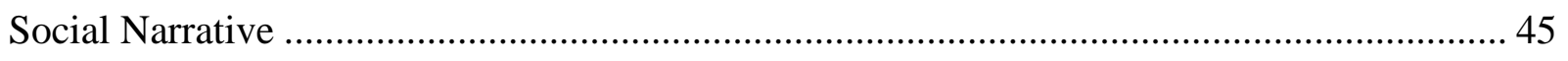

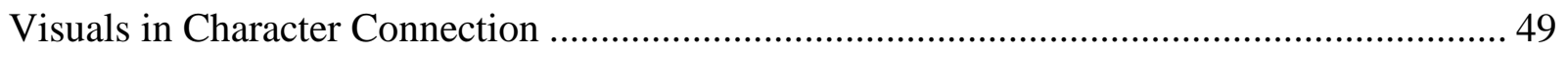

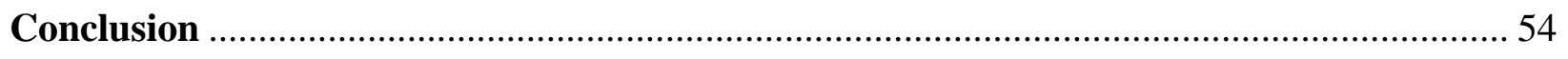

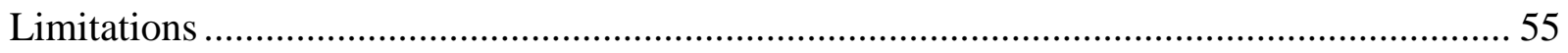

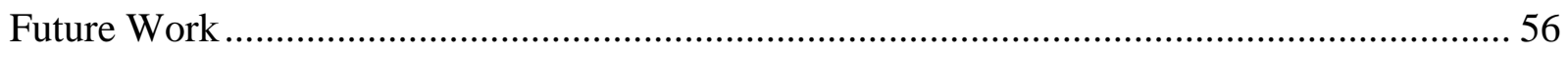

Appendix A - Dungeons \& Dragons Fifth Edition Character Sheet.................................. 57

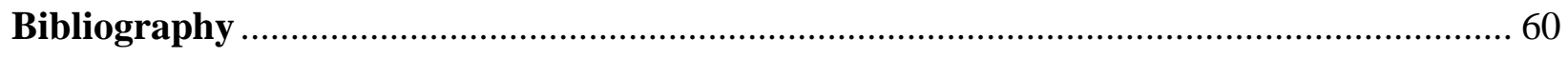




\section{List of Figures}

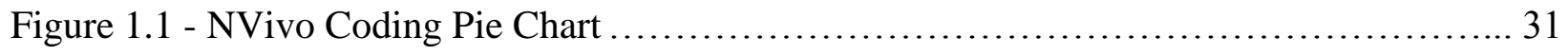

Figure 2.1 - Nvivo Tree Map of Coding References......................................... 39 


\section{List of Appendices}

Appendix A - Dungeons \& Dragons Fifth Edition Character Sheet......................... 56 


\section{Introduction}

I have been playing games since I was a kid, mostly card games, but I also have an original Gameboy when I was younger. I grew up on a family farm with my three older brothers, my parents, and my grandparents. My parents owned a cabin in the forest and I can remember many summer nights sitting around our dining room table playing Rummoli trying to figure out who I was as a person. Gaming has been a part of who I am for as long as I can remember, and it has been a part of my family for just as long. To this day I still play games with my brothers because it is what we know and how we connect to each other.

I started playing Dungeons \& Dragons in early 2014 with a group of long-time friends. My friends and I wanted a reason to get together on a regular basis and when our Dungeon Master suggested we try Dungeons \& Dragons we all jumped at the chance to play. I quickly realized how much I had underestimated the game: there was more to it than geeks getting together weekly to fight monsters. I learned that the game was about building a character and creating a narrative with others that would allow you to feel compassion for your player and want to see them mature. Dungeons \& Dragons became a whole new way to play a game allowing players to exercise their creativity and storytelling (Harrigan, \& Wardrip-Fruin, 2007). Although multiplayer games have been around since 3500 BC, in 1972 Dungeons \& Dragons created a whole new genre of gaming, the fantasy role-playing game, and has since inspired the early video games and even the modern massive multiplayer online games (Pearce, \& Artemesia, 2009; Kline, 2003).

Dungeons \& Dragons down to its core is about social gaming and people getting together to work towards a common goal, usually saving the town and the townsfolk from a dragon. 
However the game is so much more than just fighting people and gaining levels and experience. Rather, it is about storytelling and creating a story with other players within a given framework set up by a Dungeon Master (Harrigan, \& Wardrip-Fruin, 2007). The game lets you exercise your own creativity and facilitates a feeling of closeness to those you are playing with, in turn creating a truly social experience (Ewalt, 2013). The character you create in Dungeons \& Dragons can be a reflection of not only you individually but as you within the group dynamic, thus making the game an interesting topic for research into identity creation.

Wherever there is a game there is a player, and the relationship a player can create with their gaming avatar can be a deep connection lasting for years or a short one that last for minutes (Boudreau, 2007). Many people who play Dungeons \& Dragons create a character and play them for years, growing an attachment to their avatar and to their storyline as a whole (Ewalt, 2013). This research paper looks to identify what aspects of character connection players who play the game Dungeons \& Dragons connect to and how they build out their fantasy role-playing character.

This research will address two major questions with regards to avatar identity in gaming. First, how does the use of a premade characters affect avatar identity and secondly, how do visuals affect avatar identity. In a previous study done by Adrienne Shaw (2010) with regards to premade characters it was found that players tend to feel less connected to the character and more to the storyline when characters. With regards to visuals it has been shown in previous work that visuals allow players to feel more immersed in gameplay thus feeling a strong connection to the character they play (Ewalt, 2013; Turkay, 2013; Babu, 2012). Although 
research has been done on both of these topics separately they have not been studied cohesively within one paper which is what this paper looks to discuss.

This research paper begins with an analysis of research in the field of avatar identification completed by scholars such as, Kelly Boudreau (2007), Adrienne Shaw (2010), David M. Ewalt (2013), and Harrigan, \& Wardrip-Fruin (2009; 2007). These pieces of literature will help build an understanding of how players build identity and create connection to their gaming characters in both analog and digital gaming contexts. Focusing on character customization, narrative, social gaming, and the use of visuals in analog role-playing games, my research involves a participant observation of people playing the game Dungeons \& Dragons followed by interviews. Interview data was thematically coded in NVivo to understand what kind of connection players felt to their characters, both with and without the assistance of visual cues during gameplay. This paper will detail the research results starting with a literature review on identity in gaming, followed by a methodology section detailing the structure and design for the study and finally a discussion and analysis of the research findings that suggest visuals and premade characters do play a role in the participant's ability to connect to their characters.

Identity creation is a journey that starts when one chooses to play a game, and never truly ends. Identity is a process that players go through when they play a game either by themselves or with others, creating communities and building relationships. The relationship between a person and their gaming character can be strong and full of emotional attachment. It is this attachment that it is worth exploring further, particularly in an analog role-playing game environment. This research plans to explore character identity through the eyes of four players who play the game Dungeons \& Dragons. 


\section{Literature Review}

No understanding of avatar identification in gaming would be complete without a discussion of the literature surrounding identity both generally and in a gaming context. The goal of this literature review is not to be an exhaustive review of theory in social identity, community, narrative, or the issues of structure in gaming but rather to lay the theoretical groundwork for the research that lies ahead. This literature review will discuss the history of gaming, identity and identification both for gaming avatar and as a general context, character customization, community, social gaming, narrative and finally the difference between analog and video gameplay including the structure and design of the games and how the visual can affect one's ability to identify with their character.

\section{History of Role-Playing Games}

Role-playing games (RPGs) are defined as a game in which players take on the roles of imaginary characters who engage in adventures (Waggoner, 2009). Unlike board games, or even some video games, role-playing games give way to extensive character creation and customization (Ewalt, 2013). Developed in 1972, Dungeons \& Dragons was one of the first role playing games, thus establishing a whole new genre of entertainment (Kline, Dryer-Witheford, \& De Peuter, 2003). Dungeons \& Dragons is a paper and dice based analog game that allows for creativity and imagination both from the players and the Dungeon Master. The Dungeon Master is the creator and controller of the game as they set the rules and parameters for gameplay and design the basic structure of the game for their players to play through (Ewalt, 2013). However Dungeons \& Dragons gives control and creativity to the players of the game, thus the game is 
built on creativity and imagination where play starts off unstructured and then becomes increasingly structured as the game moves along (Harrigan, \& Wardrip-Fruin, 2007).

The first virtual, or digital RPG was created in 1982 with a virtual version of Dungeon \& Dragons (Waggoner, 2009). Since the initial virtual RPG many companies started coming out with their own virtual RPGs, with the second batch of games being released in 2007 (Waggoner, 2009). In 2007 companies introduced both multiplayer virtual RPGs such as EverQuest, World of Warcraft, and more, and single player virtual RPGs such as Final Fantasy and Mass Effect (Waggoner, 2009). Virtual RPGs added a whole new aspect to gameplay as now the Dungeon Master was played by elaborate computer software and no longer needed creativity and imagination from the players (Waggoner, 2009). Virtual RPGs took the fun of creativity and gave it structure because the game designers became the ones forcing their imagination on player through the use of coded systems. Within analog gameplay the players are called player characters or PCs but in the virtual RPG world players are known as avatars. Both PCs and avatars are based on the player's personal preferences within gameplay and can lead to blending identities between both the player and their gaming character.

\section{Why Identity in Gaming Matters}

Gaming has been around since $3500 \mathrm{BC}$ and has evolved from analog games to massive multiplayer online games (Pearce, \& Artemesia, 2009). Although the medium of play has evolved over time, players have always needed some motivation in order to start and finish a game whether it was single or multiplayer (Pearce, \& Artemesia, 2009). One of the major motivations of play is the feeling of being connected to the game and immersed in gameplay as a whole thus making identity within gaming important for player immersion (Pearce, \& Artemesia, 
2009). In order to understand why people play games and get immersed in games we must first have an understanding of identity in gaming and why players are motivated to create characters to look or act a certain way (Boudreau, 2007).

Identity matters because it is the construction of yourself into a character. Whether we construct characters to be separate from ourselves, or we construct them to match ourselves, we still have a part in creating that character a certain way (Boudreau, 2007). Identities are also constructed as we play through a game, by whether we choose to play with or without people, and can be enhanced through customization and visuals (Shaw, 2010). For example, studies have shown that when we take away customization and visuals many players feel less inclined to play the game and thus lose a connection to their character (Chung, 2013; Turkay, 2013; Shaw, 2010).

\section{Avatars and ldentity}

In digital RPGs, players create their own gaming avatars known as the "computergenerated body" within a game (Boudreau, 2007). In this context, recent game studies have indicated that having the ability to control the characteristics of one's avatar increases a player's ability to feel a connection to their character and to identify with them (Ewalt, 2013; Bowman, 2010; Shaw, 2010; Ducheneaut, et al., 2009; Waggoner, 2009; Boudreau, 2007; Harrigan, \& Wardrip-Fruin, 2009; 2007; Kline et al., 2003). As shown in a study by Ducheneaut, Wen, Yee, \& Wadley (2009) players want to be able to build and play their 'ideal selves', thus an avatar or gaming character can be a vessel through which players can choose to experiment with their personality (Ducheneaut, et al, 2009). It has been shown that some players will try to show the 'best' of themselves through the game (Ducheneaut, et al, 2009). 
Nonetheless not all players chose to build a virtual representation of themselves, some players decide to build an idealized version of some aspect of their life they wish could be different (Boudreau, 2007). When discussing building an idealized version of yourself many players will choose a character that they could not easily be in their real life.

Boudreau found the following (2007):

A player is able to experience the sense of what it is like to be something other than what they are. By being able to see the world through a gnome's vantage point, or experience the irregular walking patterns of a lizard, the player is able to experience a different physicality not possible in their everyday, physical lives. (p.34)

This quote outlines player preferences showing that many like to play a character that is different from themselves to see what life could be like if they themselves were different. People identify with different aspects of themselves and therefore by deciding to look at life a different way within a game it does not mean they do not identify with that aspect, it simply means they are curious about what life could be like. Fantasy is an interactive part of identity where we create an idea of our 'ideal' selves and then decide what that ideal self is within a game. Games allow players to push the boundaries of identity and to look at ourselves as someone else. Turkle (1995) discusses this best when she discusses her work into Multi-User Dungeon (MUDs) games, mainly text based. She believes that identities become fragmented and blend together, but we can also end up creating something online that we generally want to hide from the non-virtual world (Turkle, 1995). Since the internet is flexible and we end up creating personas, we are able to create what we want and make others believe that is who we are (Boudreau, 2007; Turkle, 1995). With creativity and flexibility people find themselves creating characters that they would 
not normally create in the non-virtual world whether it is something we would be ashamed of if our parents found out or if it was something to protect us and our emotions (Boudreau, 2007; Turkle, 1995). Our created identities, whether hybrid or fantasy, end up being dynamic as both we in the non-virtual world change but also because we want to try out something new (Turkle, 1995). Players build identity in games as they try to figure out who they are.

\section{Identity and Identification}

Identity is known as the representation of one's own expression of themselves and of their community affiliations. This is also known as their culture and how one is "distinguished in their relations with other individuals and collectivities" (Jenkins, 2008, p. 18). Identity stands as "something that one does" it is not simply "something that one can have, or not" (Jenkins, 2008). Given that identity is something we do, it is also seen as a part of the process of identification, which is regarded as a process of taking on something as your own (Jenkins, 2008, p.5). Within games, players tend to take on the identities of their character as their own, creating specific roles and characteristics that mimic their personality (Li, Liau, \& Khoo, 2013; Bowman, 2010; Shaw, 2010; Ducheneaut, et al., 2009; Waggoner, 2009; Boudreau, 2007).

Identification differs from identity because identification is about you establishing significance between yourself and other individuals as well as communities and those within them (Jenkins 2008). The process of identification is where blended identities start to emerge, known as hybrid identities. Hybrid identities are a representation of both you and another identity you have taken on where instead of having two separate personalities you have one that is meshed together (Turkle, 1995). Game rules, roles, and structures lead the way to hybrid identity creation allowing players to not only create themselves in a virtual form but be able to 
play out their fantasies (Turkle, 1995). Role-playing games give players a heightened ability to create hybrid identities since players are expected to take on the role of the character they are playing (Harrigan, \& Wardrip-Fruin, 2007). Within role-playing games players customize their characters as per the game design allotment and then are expected to take that character, level them up, and create a life for them. Within some games, players have the ability to choose their class, race, facial features and more, giving them a chance to build a version of themselves in the virtual gameplay (Boudreau, 2007). By being able to build out a version of themselves players tend to make character connection a visceral experience. Players get attached to their characters and want to see them succeed as they level up and grow within the game.

Together, identity and identification are dynamic just like human personality, our world gets shaped by our environment and is changing constantly day to day (Jenkins, 2008). Within a game, identity is continuously shaped through structure and game design. In the book Second Person the discussion of game structure leads way to explaining this by stating "stories are most structured after they are told" explaining that many stories start off broad and undefined but once details are added, and the story progresses, the narrative takes shape and becomes more defined (Harrigan, \& Wardrip-Fruin, 2007). This also rings true for identity; as a player moves through a game they come into contact with other players, and gain accomplishments which give their character meaning. That meaning is gained through the structure of the game and helps to shape the player's identity within the game both to themselves and to their community (Harrigan, \& Wardrip-Fruin, 2007). The idea of giving your character meaning is shown within the narrative of the game Dungeons \& Dragons (Ewalt, 2013). As players move throughout the campaign they come into contact with other non-player characters and learn more about the game narrative 
strong thus giving their character more meaning within the context of the game itself (Harrigan, \& Wardrip-Fruin, 2007).

Another example of giving meaning to one's character is found in the character narratives (Ewalt, 2013). When players create a backstory for their player, or are given one, it creates meaning to their gameplay and thus gives them motivation to play. Within Dungeons \& Dragons motivation changes throughout gameplay; one player may start off wanting to explore the world but they may realize that it is not getting them anywhere in the game so they change their motivation to something that will advance the storyline. Motivation for player's choices are based on their connection to the game and their ability to be immersed in gameplay. That immersion for the player depends on how connected they are not only to the story itself but to the player they are playing, thus the ability to create a character or be given one can affect how someone connects and becomes immersed in the game (Shaw, 2010)

What can be deemed as important within identity and identification is the ability to create a version of yourself that you feel represents you the best. Whether that version of yourself is a fantasy or is something that just seems like fun to you, having the ability to make a character can affect someone's ability to feel immersed in the game world (Boudreau, 2007). Within the context of a game this is done through character customization, which means that players have the ability to pick and choose what aspects they want of their non-virtual identity to be shown in their avatar (Ducheneaut et al., 2009). By giving players the ability to customize their avatars they tend to have a better chance of identifying with the character (Ducheneaut et al., 2009). 


\section{Customization within Avatar Identity}

Customization within games can range from choices in how to play the game to choice in how your character looks within a game (Boudreau, 2007). With regards to identity, customization allows players to make the character they are playing feel a part of themselves creating a hybrid identity interconnecting both their virtual and non-virtual lives. Within the game Dungeons \& Dragons customization refers to how you build a character and how that character helps shape the game (see Appendix A) (Ewalt, 2013). Since Dungeons \& Dragons is a paper based game, customization refers to the skills, traits, ability scores, class, race, and other aspects that can be found on a classic character sheet (Ewalt, 2013). When players create a character from scratch they give meaning to their character by building something they take joy in playing and that they want to see advance within the campaign run by the Dungeon Master (Ducheneaut et al., 2007).

Customization of any kind is important for identity creation in a game because it gives players a sense of having choice (Kline et al., 2003). Players want to feel like they have a hand in the game whether it is by choosing to customize their character, choosing to be good or evil, or just general choice in gameplay (Kline et al., 2003). Choice also gives meaning to the players and allows the players to connect to those choices thus feeling more involved in the game as a whole. However some games do not allow for choice, some games give players a premade character and tell them to play.

Premade characters within a game add a different level to identity construction as players are expected to play the person who has been put in front of them. Players tend to connect to premade characters through the story and actions of the character however their connection is not 
found to be a deep one (Shaw, 2010). In fact, Shaw (2010) found that players prefer to build their own characters rather than being given a premade character because, if they build their own character, they tend to feel a larger sense of ownership in the character and want to see them succeed. The connection to the premade gaming character is not made on an emotional level but through the idea of taking on the player's role. In virtual gaming, it has also been noted that "people identify as the on-screen premade character, in the sense that they are taking on the character's role in the game world, but they do not identify with the character in an emotional sense" (Shaw, 2010, p. 148). This shows that when playing a premade character, players tend to connect with the actions of the character as opposed to blending their identity. This is mainly due to the fact that customization, as discussed previously, is an important aspect of identity creation and without it players cannot bond with their characters as effectively. An emotional connection is formed when a player gets to create a version of themselves, and they take on that identity as their own.

Emotional connections within a game can be both a positive and negative experience. In fact, emotional connections can help players immerse themselves in the gameplay (Shaw, 2010). However an emotional connection can be harmful if anything negative happens to the character. Since avatars are in-game embodiments of the players, people tend to grow a connection with their avatar on an emotional level, getting upset if something happens (Wolfendale, 2007). Players become emotionally connected to avatars, and want to see them level up and create relationships with other avatars; even noting that "[p]hysical proximity between avatars can ... signal intimacy and friendship, just as bodily proximity does in offline life" (Wolfendale, 2007, p. 4). Therefore players tend to take on a role within their society and community group that will 
help them identify with their avatar. When players have the ability to create their own characters they then form a bond with those characters and much like in the non-virtual life they will go out and find other players to help them advance their identity and to feel like a part of something (Wolfendale, 2007).

\section{Identity within Gaming Communities}

Just as in real life, players build their identity based on both who they are, who they want to be and based on their community and social norms. Community, in a sense, is the search for belonging within a modern world full of insecurities where people will look for a place to fit in (Delanty, 2003). During the process of finding a place to fit in people will construct identities to fit what others expect from us. Players in a role-playing game want to find a place to fit in and to be accepted but also will mold themselves to fit what their community expects from them. Boudreau (2010) believes that once you get a character and an avatar you are bound both by structures of the game design and also by the structure of the social norms within the game. Players are bound by these elements as they must play the game as per the rules and structure set forth by the game designer but also by the rules and expectations set forth from the community (Boudreau, 2007).

Despite an adherence to both design structure and social structure within gameplay, our roles within the game are dynamic, which leads the way to a more dynamic identity. Roles are constantly changing and our identity must change with them. The roles within a gaming context are something the players choose when they choose their character's class or race (Boudreau, 2007). A class within the game defines a player's abilities, strengths and weaknesses while a race defines the nature of the character and their basic background (Boudreau, 2007). With regards to 
the dynamic roles, a player of Dungeons \& Dragons may identify as a cleric class or a healer who is responsible for healing the group but if they turn out to be using their powers for evil they will no longer be seen as a positive player. The different roles you may play in a game can affect the way you embody each role.

As stated in Boudreau 2007:

The player who plays more than one character (of a different class) can indeed define themselves as more than just a cleric, or just a warrior - but as a unique hybrid of both, since the player will accumulate knowledge from one character that may potentially affect their definition of self when playing another character. (p. 69)

Since many players do not just have one character to play, they are constantly blurring the lines of identity within the game. Players generally have more than one character within a game and switch between identities when they either want a new experience or feel bored with their current gameplay (Boudreau, 2007). When players actively shift from one skill set to another they tend to still bring in previous experience and knowledge from the other skill set to play the game. They become a hybrid of both characters as they understand how to play the game as both characters.

When a player takes on a specific role within the game, and decides to play with other players within the game, they are expected to understand and abide by the rules set forth by the community. These rules may be directly stated, such as when pressing one button will get you a certain outcome, and these rules may also be indirectly stated, such as do not harass each other (Boudreau, 2007). These rules within the game gives structure to play but also builds structure 
into the identities we can create within the game. By being able to play with other players and to level up our characters we create a game that is not purely a personal experience but also a social one that determines not only what we say or do but what we decide to do in front of other players (Harrigan, \& Wardrip-Fruin, 2007). It is said best in Second Person when discussing how players shape their identities and talking about how avatars and characters end up evolving within communities and within a social context because social norms end up having an impact on who the player is (Harrigan, \& Wardrip-Fruin, 2007). Groups motivate players to be better than themselves and to go beyond the game design to create a unique skillset that will allow the group to advance in gameplay which is given to players through group socialization (Harrigan, \& Wardrip-Fruin, 2007). The interactivity within games allow for re-embodiment for players which allows them to identify with their characters and enhance their virtual experience (Harrigan, \& Wardrip-Fruin, 2007).

Identity is created through the player, the community they belong to, and the designers who create the game (Li, Liau, \& Khoo, 2013; Harrigan, \& Wardrip-Fruin, 2007). The designers of the game are the ones who get to choose the type of customization allowed for a character, whether you get a premade character or if you get to change almost everything (Kline et al., 2003). Designers and artists take concepts and make them into realities which players choose to emerge themselves in (Kline et al., 2003). Game designers work at building a game that will satisfy a player's need for achievement, rewards, and to ensure that they can feel like the game is a part of themselves (Kline et al., 2003). When players make conscious decisions in games they are giving meaning to the game structure and building their avatar's identity within the game. 
Within Dungeons \& Dragons the Dungeon Master plays both the role of the game designer and the ruler of the game who creates the rules of play based off a framework provided by the game mechanics (Harrigan, \& Wardrip-Fruin, 2007). The Dungeon Master can either design a storyline from scratch or take a premade one from another designer and incorporate it into play, either way the story will evolve through the creativity of those playing the game making the story and narrative their own (Harrigan, \& Wardrip-Fruin, 2007). When the Dungeon Master allows players to take a game design and create their own path, the players are given the ability to choose how the game is played, within limits, and thus they feel a greater connection to the game and to their characters (Harrigan, \& Wardrip-Fruin, 2007). Creativity in gameplay does not just come from individual player creativity but also through other players and the game design as a whole. Since Dungeons \& Dragons is meant to be a group storytelling experience the game itself is built on social and human connection thus making play a social gaming experience (Ewalt, 2013).

\section{Social Gaming}

Social gaming refers to the act of socialization either as required or by choice within a game whether it is analog or video (Pearce, \& Artemesia, 2009). Generally social gaming has referred to the games people play while on social networks, however it has been around since early tabletop days when players used to have to be in the same room in order to play a game (Pearce, \& Artemesia, 2009). Before video games and online digital games were invented, the vast majority of gaming was multiplayer where people were forced to be in the same room as each other working towards a common end point such as chess where you are required to capture the king pin (Pearce, \& Artemesia, 2009). Dungeons \& Dragons was developed during a time 
when fantasy narrative was popular and when video games were just starting to be explored and developed (Pearce, \& Artemesia, 2009).

Dungeons \& Dragons itself is a social tabletop role-playing game where players are expected to be in the same room as each other working towards the same common goal as a group or guild (Ewalt, 2013). Although Dungeons \& Dragons has been created in an online digital version, players still prefer the traditional tabletop version as most enjoy the need to socialize with other players (Ewalt, 2013). Aside from being physically present, tabletop roleplaying games allowed players to stretch their creativity with each other (Harrigan, \& WardripFruin, 2007). Given that Dungeons \& Dragons is a cooperative game, players prefer to be together when playing because they are working towards the same thing as opposed to working against each other (Ewalt, 2013). Dungeons \& Dragons is meant to be a game where players feel comfortable with their imagination and with other players, which generally means players want to be in the same space as others so they can play off each other's actions within the story (Ewalt, 2013). Due to this, many Dungeon and Dragons groups have known each other for years and are comfortable with them as friends and people because one bad player can derail a campaign and make other player feel uncomfortable during gameplay (Ewalt, 2013). It is common for groups to get together for years playing the same character and doing the same campaign because the game is not meant to be won, it is meant to be a creative and social experience (Harrigan, \& Wardrip-Fruin, 2007).

Dungeons \& Dragons is a table-top narrative based game where players are expected to follow a campaign set out by their Dungeon Master as well as create the story themselves (Harrigan, \& Wardrip-Fruin, 2007). Hence players generally prefer to be in the same space as 
each other so that they can easily, without delay, advance the story and get immediate feedback from the Dungeon Master (Kline, 2003). If one player is not working towards the same goal as their companions the game can become derailed and players can become frustrated, thus many groups have played together before and when introducing new players into the group give them a trial period much like a job (Ewalt, 2013).

Social gaming has been around since $3500 \mathrm{BC}$ and is still prominent in today's digital era where people are choosing to play with people online (Pearce, \& Artemesia, 2009). Gameplay has focused on how to build an experience for the player but most of those experiences to this day still revolve around how they can experience play with others (Pearce, \& Artemesia, 2009). Narrative also plays a role in connection within role-playing games as role-playing is all about building out a fantasy (Shaw, 2010). Within Dungeons \& Dragons the narrative of both the campaign itself and the character backstory can play a role in how players build motivation and connection to their gaming character (Shaw, 2010).

\section{Narrative in Connection}

Dungeons \& Dragons is a narrative based role-playing game where not only do players have to be immersed in a story but they also have to create a story for their character (Ewalt, 2013). Role-playing games have been a medium for storytelling since the start and many have tried to replicate that experience in video game (Harrigan, \& Wardrip-Fruin, 2007). The idea behind narrative in role-playing games is that it never has a true end or a true path, it is meant to be imaginative and created by the group telling the story (Harrigan, \& Wardrip-Fruin, 2007). Dungeons \& Dragons is played where the Dungeon Master gives players a basic understanding of what is going on in the game and then they the Dungeon Master lets the players shape the 
game how they want and not how the Dungeon Master wants them to (Harrigan, \& WardripFruin, 2007).

Storytelling is a large component of Dungeons \& Dragons. When a player creates a character they need to create the meaning behind the character, which can be referred to as authoring the character (LeBron, n.d.). Within video games the authoring is already built in even if players are given choices on how to advance the narrative in the end it is still a coded structure (LeBron, n.d.). Dungeons \& Dragons still gives the players the ability to author their player characters building out who they are, the skills they have, and where they came from (Ewalt, 2013). If that authoring aspect is missing in a game some players can feel less connected in their role play because a critical piece of connection was taken away from them (LeBron, n.d.).

Players are forced to really think about their player character when they draw out their own backstory. The backstory within Dungeons \& Dragons forces a player to think about what happened in the character life to get them to the point of starting the campaign (Ewalt, 2013). By building the backstory players have to really think about who their character is and how they got where they are, thus giving them a strong connection to the character as they have to build out who they want the character to be before starting the campaign (Ewalt, 2013).

Most games, even role-playing games, do not necessarily require the player to build a backstory for their character - some are given to them and some just want you to pick and choose once you start to create a narrative along the way (LeBron, n.d.). How the game is structured and designed plays a role in how much choice a player has, thus creating rules for how much a player may be able to do during play (Harrigan, \& Wardrip-Fruin, 2007). Some games allow for players 
to create narratives and play together while others are more structured and choose to emphasize visuals over creative and imagination from the player (Harrigan, \& Wardrip-Fruin, 2007).

\section{Visuals in Gameplay}

One of the main parameters that can be set by the designer is the visual component of the game itself. Within a paper based tabletop role-playing game visuals are rarely used and if they are used they may not match what the player envisions (Ewalt, 2013). In contrast, within a video game, visuals are the leading force of gameplay giving players the ability to control a character either in a first person perspective or a third person perspective, however the game is still constructed on visuals (Waggoner, 2009).

Visuals within video gameplay makes way for immersion thus giving players the ability to identify with their characters in a fast paced, more robust way (Ewalt, 2013). When players create characters from scratch they tend to take their time building a character that they can feel connection to. This connection can come in many forms but mainly players see their non-virtual identity bleed into the character's identity with the focus being on who the character is and how they act or the narrative (Ballsun-Stanton, \& Russell, 2012). Given that video gameplay is preprogrammed, players spend more time customizing characters based on their visuals, however within an analog gameplay, players must create all aspects of their player from skills to background and more. The lack of structure within analog gameplay makes the player spend more time contemplating their character customization, and spending less time on how the character may look (Shaw, 2010). However within some video games, character customization is one of the most important aspects of the game and players are given the chance to customize 
everything down to hair colour (Ducheneaut, et al, 2009). Visuals can play a role in how players can connect to their avatars and connect to other players.

In our culture we have shifted from text based computer displays focusing on text to a visuals based computer system for information such as the graphically enhanced operating systems we have today (Turkle, 1995). Games have constantly evolved from the first simple games like chess to role-playing fantasy games like Dungeons \& Dragons to massive multiplayer online games (Pearce, \& Artemesia, 2009). Computer games on the other hand have evolved from text based play to the visual play much like the evolution of operating systems (Turkle, 1995). Visuals have found their way into our everyday lives from pictures to visual computer displays and our culture has become increasingly reliant on the way things look (Turkle, 1995). Games are no different where many players find themselves wanting the visual games because players can get a better understanding of the game and can focus on becoming immersed in gameplay (Waggoner, 2009). However visual or non-visual players still find ways to play games and connect to their avatars, visuals can just help facilitate that connection (Ewalt, 2013).

Players have different motivations for playing games and connecting to their characters. Some choose to connect through visual representations and some choose to connect through how they build the character out. The remainder of this paper looks to study how participants playing the game of Dungeons \& Dragons and the connection to their characters. This was studied through four gaming sessions once a week for a month where I myself played the role of the Dungeon Master taking players through the story and watching them connect to their avatars. 


\section{Methodology}

In order understand how players connect to their character in an analog role-playing game, this study employs multiple methods to gather information related to the popular game Dungeons \& Dragons. This research draws mainly from Kelly Boudreau (2007), Shaw (2010), and Ewalt (2013) in its approach. The research involves three main methods; an observational study, in-person interviews and auto-ethnographic reflection.

The following is a description of each of the research methods, examples of where they have been used in prior research, and how this study employs them. Each method will be described briefly to give the reader an idea of how the data was collected and why it matters for the purpose of character connection. Not all of the data collected is present in this thesis however this is an accurate representation of how those who chose to participate view their own experience in character connection.

\section{Observational Study}

An observational study is where researchers watch individuals in any environment focusing on their naturally occurring behaviours. Although the study focuses on natural human behaviours the setting of the study can be a variable which allows for researchers to test out theories on how environments can affect human behaviour (Banister, Bunn, \& Burman, 2011). Observational studies are used within research to allow participants to experience interactions naturally, thus allowing researchers to monitor those reactions and to learn how to see the interaction through that individual's perspective behaviour (Banister, Bunn, \& Burman, 2011). 
Observational research is rich, allowing for the authors to include their perspectives as well as perspectives of their participants and how they reacted to the environment at hand.

Observational studies have previously been used in gaming research to understand how people can react to changes within a gaming environment (Waggoner, 2009; Tse, Greenberg, Shen, \& Forlines, 2006). Within Tse et al's (2006) research on how digital gaming environments impact social gaming the researchers observed players in both analog and digital gaming environments to see how the environment impacted socialization (Tse et al, 2006). This allowed the researchers to understand body language, the use of socialization within gaming environments and how an environment can affect a player's ability to socialize with others (Tse et al, 2006). Another instance of observational studies into gaming comes from Zack Waggoner in his book My Avatar My Self: Identity in video role-playing games (2009) where he interviewed and watched players of different experience levels connect with their avatars in digital games. Waggoner (2009) watched participants create and play characters in video games while he watched the participant's natural gaming style and actions. This study design is different because it brought participants together into a private room changing aspects within the study but kept the physical location the same every week.

In all three studies (including this one) the rationale for conducting the study was in watching the participant's natural behaviours (Waggoner, 2009; Tse, et al, 2006). By allowing participants to play games and react as they naturally would, researchers can have a greater understanding as to why players do what they do in the game itself (Banister, Bunn, \& Burman, 2011). This study is no different, it was designed to give the researcher the ability to understand the participants during gameplay. Focus for this research was on how the players reacted to 
certain situations and when they faced challenges what they do to overcome them in both the game itself and character connection.

Following Tse, et al (2006), Banister et al (2011) and Waggoner (2009) the observational study designed for this research focuses on how the players interact with each other and with their character. Although watching the participants in the game allows for the researcher to add in personal perspectives and scenarios from the gameplay to make the research richer, the research still needs more context to be understood. Therefore interviews were conducted following the observational research with participants to make sense of their behaviours while playing the game of Dungeons \& Dragons.

\section{In-Person Interviews}

Interviews within game studies are an integral part of qualitative research driven studies. Interviews allow researchers to make sense of the data at hand, thus many pieces of literature involve interviews to bring context to any data collected (Ewalt, 2013; Bowman, 2010; Shaw, 2010; Ducheneaut et al, 2009; Waggoner, 2009; Boudreau, 2007;). Interviews are used because they allow researchers to make sense of what the participants were feeling or thinking while in the moment of the game much like in Waggoner (2009) where he asked his participants why they chose a specific action over another to make sense of their thinking behind decisions. Interviews allow the researchers to use questions, usually open ended, in order to pull out information from the participants, thus gathering richer data for analysis. Interviews can be done in a variety of ways including different locations, allowing participants to find where they feel comfortable to talk about situations, different number of participants, allowing for a more broad understanding 
of the research topic, and virtual or in person depending on what suits your study and what works for your participants.

Both Adrienne Shaw (2010) and Kelly Boudreau (2007) used interviews for their research. Shaw had a mix of in-person and virtual interviews depending on what the respondent was able to do whereas all of Boudreau's interviews were virtual given that she wanted to study the virtual nature of online games (Shaw, 2010; Boudreau, 2007). Both styles of interviews yielded suitable results for the researchers however Shaw's in-person interviews allowed her to create an understanding for the reader of where the respondent was and who they were (Shaw, 2010). By being able to use narrative with regards to her in-person interviews her research created a richer context for her readers (Shaw, 2010). The in-person interviews for Shaw allowed her to understand the context of the players in the environments as well seeing where they felt more comfortable and where they were able to remember scenarios since occasionally objects can trigger memories (Shaw, 2010). By conducting her interviews in-person Shaw could see the gamer and understand them in a clearer way getting the whole picture from where they live to how they play the game itself allowing her to create a more contextual analysis of how the gamers felt while playing the game (Shaw, 2010).

For the purpose of this research interviews were conducted in person and in the same location as the gaming sessions. In person interviews were chosen as a format to add context to the writing of this paper by setting a scene for the readers much like Shaw (2010). Participants were also asked to come back to the same location as the gaming sessions for their interview to give them the ability to remember game scenarios in the location that the game took place. During the interview many participants were able to remember scenarios and participants' 
character names better when they could point to the spot and think of a certain time within the campaign. By doing this, participants were able to remember the game better and give more detailed answers to the questions. However, due to the small sample size, auto-ethnographic reflections will be used in research to give the reader a better understanding of how gaming identity is perceived through both the participants and the researcher.

\section{Auto-ethnographic Reflection}

Finally, this study will involve the use of auto-ethnographic reflection for additional contextual data. Auto-ethnographic research follows the traditional auto-biographical writing but focuses on the ethnographic or the research into behaviours and culture (Banister, Bunn, \& Burman, 2011; Boudreau, 2007; Denzin 1997). Auto-ethnographic research has an emphasis on how an individual feels about a certain situation which revolves around their personal experience, feeling, and behaviour towards that situation (Boudreau, 2007). By adding in the researcher's perspective the research is creating a more immersive experience for the reader (Boudreau, 2007). Since this research revolves around the ability to create hybrid identities between one's avatar consequently creating an immersive narrative within this paper allows readers to have an insight to the game of Dungeons \& Dragons.

Auto-ethnographic research is found in both Ewalt's book Of Dice and Men (2013) and Kelly Boudreau's paper Pixels, Parts \& Pieces: Constructing Digital Identity (2007). Ewalt uses the experience of play to create a narrative within his book that stood apart from the research itself (Ewalt, 2013). By creating this secondary narrative within his book Ewalt (2013) gave his readers and understanding of how the game is played from discussing the history of Dungeons \& Dragons to digital alternatives found today. In order to do this, Ewalt (2013) added in his own 
auto-ethnographic reflection from gameplay taking readers through both the research as well as his own gaming experiences playing a cleric within the role-playing game. The autoethnographic reflections created a narrative within the narrative making the readers feel a part of his experience of playing the game Dungeons \& Dragons with his group of companions (Ewalt, 2013). Boudreau (2007) herself used auto-ethnographic reflection to add in her perspective of building an online identity, which was supplemented though player interviews. Boudreau's (2007) reflections were added into research in order to "construct and contextual narrative" for her research question.

Much like Ewalt (2013) and Boudreau (2007), the auto-ethnographic reflections used for this research are to create a narrative that will add context alongside the participant responses. In order to collect theses reflections, notes were taken during gameplay for both tabletop and video gameplay. These notes are supplemented with research on the game, the history of the game, as well as personal history with the game such as years played, games played, and experiences within a given timeframe. These notes serve as added material for research taking personal reflections and comparing them to reflections received from participants within the observational study. This perspective gives context to why the topic is being researched and how different types of players can approach character connection.

\section{Study Design}

The study conducted for this research involved all three of the above methods and was conducted with a convenience sample of four participants. A sample of four participants was used due to both the mechanics and design of the game Dungeons \& Dragons given that the ideal size of a well-rounded group is four participants permitting you to have the basic group 
companions; the tank who takes all the damage, the cleric who heals everyone, the range character who also has spells they can cast to add to the cleric's spellcasting ability, and the melee character to help the tank in close up combat (Ewalt, 2013). For research purposes a sample size of four can allow the researcher to gather data which is richer since the researcher is able to take their time and pull out a wealth of information from each interaction (Morse, 2000).

The observational data was collected over four consecutive weeks of three hour gaming sessions totaling twelve hours of gaming. Within the study the researcher took on the role as the Dungeon Master and created four characters, gave the character sheets to participants, and chose a premade campaign to use as the storyline. For the game, players were given premade characters where the name, class race, abilities, etc. was all decided prior to the start of the study. However once players moved up to a new level they were allowed to change aspects of their character with given parameters. Players were not allowed to change class, race, personality traits, skills, or anything that pertained to their character's backstory once their characters leveled up but were able to edit their skill trees, ability scores, weapons, and a few other minor aspects of their character. The first two gaming sessions included no visuals as everything was done through text based character sheets and verbal storytelling alongside the die rolls. For the final two gaming sessions the Dungeon Master introduced miniatures for each character that the players chose themselves. A dungeon map and battle map were also introduced for the players to understand the context of their gaming location with regards to the storyline.

Once the observational study was complete participants were asked to complete one on one interviews with the researcher to get in depth information on how their natural experiences within the study affected their connection to their character. The questions for the study were 
opened-ended, allowing for follow up questions to be asked and for the participants to have to think about their answers. The interviews for this research were conducted in person and strategically done in the same room as the gaming sessions to allow the respondents the ability to feel comfortable with their surroundings and to have a better memory of the observational study (Waggoner, 2009). Questions for the interview were structured around the participants experience within the observational study as well as their overall experiences as a gamer. Open ended questions forced participants to really think about their responses which allowed the researcher to asked follow up questions based on information that was pulled out from the given answers. The interviews were scheduled the week following the gaming sessions and were allotted two hours for each interview although many of them did not take the full two hours.

The auto-ethnographic reflections were recorded between January and July 2015 in the form of notes written during and immediately following gameplay. These notes included information about the history of the games played, the researcher's personal history with the games played, and personal experiences. The reflections were personal in nature and did not involve experiencing the game with other players just how the researcher viewed their connection to her various characters played in various games.

Upon completion of data collection, the research from the interviews was taken and thematically coded in NVivo to search for themes related to identity in gaming (Baek, 2013; Kwon, \& Back, 2009). For example, this research was coded for instances where participants discussed visuals helping or hindering character connection, where premade characters were easier or harder to connect to, and where connection and identity was strong or weak based on scenarios within the observational study. Thematic coding is important because it allows 
researchers to identify themes in participant's responses thus creating a better basis for analysis with the given data set (Braun, \& Clarke, 2006). Both Baek (2013) and Kwon \& Back (2009) used thematic coding in their research to identify themes and groupings in their research into how gambling is an addictive form of gaming. Both researchers coded for major themes and sub themes to get the most of out their data and to allow anonymity for their participants since you can report on themes and leave participants out of it (Baek, 2013; Kwon, \& Back, 2009).

Once the data was thematically coded it was analyzed in NVivo for relationships between the participants and their feelings of identity and character connection within the game Dungeons \& Dragons. The coding for my research examines how participants felt about character connection, premade characters, customization, social gaming, and how visuals played a role in connection. The following discussion and analysis section focuses on how the participants felt about their personal ability to connect to their character.

\section{Analysis and Discussion}

The process of character connection is much like the process of understanding a game. You first decide who is playing, then who is going to be what character, then you have to figure out the rules of the game before you can feel a connection to the character you are playing. As you become more comfortable with the game and your character, you start to feel an emotional connection, thus wanting to see them advance through the storyline and you get angry if they are injured and even die (Wolfendale, 2007). As a player goes through the storyline they become attached and that first reward is enough to get them hooked on seeing their character succeed (Wolfendale, 2007). 
Within Dungeons \& Dragons, once a player has finished creating their character they set off on the journey to play the campaign created by the Dungeon Master. The participants within this study set off into The Shadowfell of the Keep a story full of demons and skeletons trying to open a portal to another world. In this campaign players were trying to come together and close a rift in a nearby fallen keep where demons were trying to wreak havoc on the town of Winterhaven and the people within it. The cleric Lia, ranger Alston, barbarian Krusk and fighter Fem were told of the impending doom and gathered together to rescue the town and to seal the rift for good. The adventurers soon set off for their journey into role-playing and character connection while trying to save the good people of Winterhaven.

This section is the explanation of what happened during the campaign and how the players developed a connection to their premade characters. The key themes that will be explored throughout this paper are the importance of customization, narrative, and visuals within identity construction as shown in this pie chart:

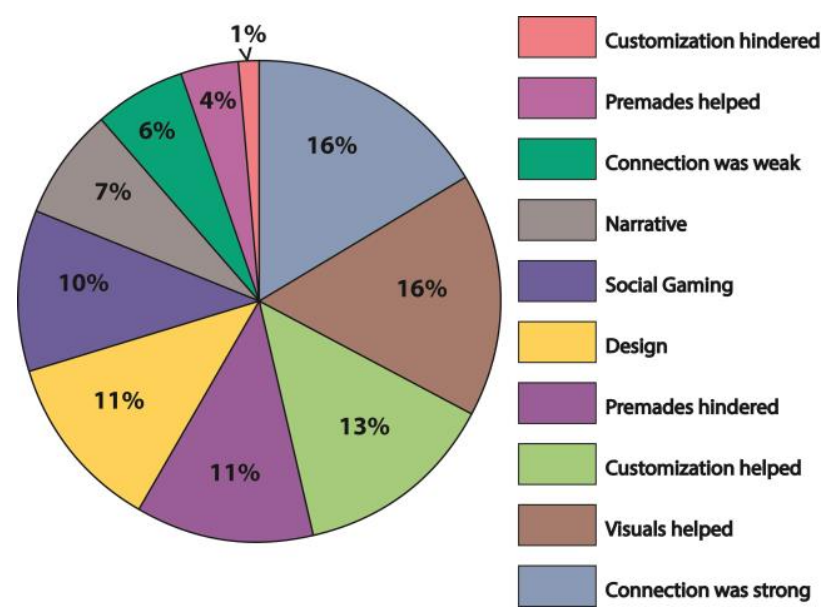

Figure 1.1: NVivo Coding Pie Chart; all pieces relate to how the participants felt the specific aspect affected character connection and how they felt the game facilitated connection. 
To start off I will explore the identity creation within the game and how participants built connections to their players, which will be followed by a look into customization and why the participants agree that customization helped them build a connection. Next I will explore narrative and backstory and how, by both building the narrative of the game and creating their own character backstory, all participants felt a stronger connection to their players, followed by narrative creation within a social gaming and storytelling setting. Finally there will be a discussion on how visuals impacted play and why the participants felt that visuals helped them better understand the context of the game thus allowing them to focus on their character and who they were.

\section{Creating Character Identity}

Building a character in Dungeons \& Dragons is no easy task. Sometimes it takes a while to build a character you can feel attached to which is why people tend to play characters for years over various campaigns (Ewalt, 2013). When players invest their time and effort into building a character, they tend to feel more attached to the character, which helps players build connection and emotional attachment to their character. As already discussed by Wolfendale (2007) emotional connections to characters can attach people to their avatar but can also harm them. When players become more attached to characters they get a sense of accomplishment, but if they are turned against they can feel emotional pain through their characters (Wolfendale, 2007).

Emotional connections can both be built with analog and digital characters and it is something I experience both with Dungeons \& Dragons and in the video games I play. When reflecting on my own gameplay I realized that when I start off playing the video game The Sims I always start off building me, Pamela Livingstone, as closely as possible because it feels 
comfortable to me. This not only allows me to build up my own character but also to get used to the game itself before I go and build crazy combination characters. By having the creativity to build myself and my identity within the game first I can feel my virtual and non-virtual identities blend, creating a hybrid identity within play (Turkle, 1995). Within Dungeons \& Dragons I tend to build characters I am comfortable with first, as well as something that I have played before and understand how to play. My first Dungeons \& Dragons character, Zakia, is a sneaky thief who focuses on long range attack and she was built this way because I play this type of character in online games such as Diablo III. By being able to build a character that I have played before and feel comfortable with the game I can then build an emotional connection to my avatar. I tend to follow what I am used to so that I can start to feel like I am playing the game and get a sense of the game mechanics before actually becoming immersed in gameplay. My personal play style is to understand the game first and understand who the character is before I figure out who the character can be and customize my experience in a more creative way.

When a player builds an emotional attachment to a character sometimes they can feel like they are the character. For example, Lia's player stated that they felt like the decisions they were making in the campaign would have been those that Lia would have made. Within the campaign Lia was pushed into the leadership role of the group but was the only lawful good character in a group of chaotic players which always resulted in the three chaotic players going against what Lia felt was right. This frustrated Lia's player and at one point made Lia decide that they did not want to heal their companions anymore. This was brought on because the other players were always going against Lia's plan, thus making Lia's player feel bad for the character, which shows that they had built an emotional connection to the character. This is an emotional 
attachment because Lia's player felt close to their character and would get frustrated when their teammates would go against them in combat. Lia's player's emotional attachment to their avatar allowed them to both build a connection and to make the character their own even when they were given a premade character. This idea is also discussed by Ching-I Teng (2010) in the paper Customization, immersion satisfaction, and online gamer loyalty when it is mentioned that when players invest time into their character they build emotional attachment and this can intensify their character connection. When Ching-I Teng (2010) discusses customization and character identity there is a lot of discussion on how customization helps players create a persona with their character thus building a strong connection and attachment to them something which is also discussed by Shaw (2010) and Wolfendale (2007).

Emotional attachment is one way to build a connection to your gaming character but players can also build connection through personality traits, which was the case for Alston's player. Alston's player is used to playing games as the evil and sly character and Alston within the game was a sneaky little gnome. When Alston was asked how they would have developed an identity with the character if the personality traits were changed they indicated that if the character was not this sly and sneaky character they would have had a hard time building a connection to the character. Shaw (2010) discusses this within her paper where her players would find less of a connection to a character they did not want to play because of their actions or the way the story moved them through the game. When a player, such as Alston, becomes used to a typical sly style in games they tend to constantly want to play that same play style as it is more comfortable to them letting them become immersed in the game and their character. 
Identity within games can come in many forms and from many parts of the game ( $\mathrm{Li}$, Liau, \& Khoo, 2013; Boudreau, 2007). Sometimes players create identity when they feel emotional attachments to their characters and some create identity through the process of customizing out their character. Lia's player stated that they preferred to build characters that matched who they were, building a hybrid identity between them and the character, however Krusk's player stated they liked to go crazy with characters and separate the character from their non-virtual life. This all comes down to customization of the character during the character creation process.

Customization can been seen as a major part of identity creation in a game where many people can either decide to build out a character whose identity matches their own, much like myself and The Sims, or players can build out a crazy character who is just fun to play with.

\section{Customizing Your Avatar}

The game of Dungeons \& Dragons requires a substantial amount of customization while building characters, and many players enjoy exercising their creativity while they build characters. To build a character in Dungeons \& Dragons you start off with an empty character sheet (see Appendix A) and you, the player, has to fill in everything down to the minute detail of your character, such as skin and hair colour.

Customization is where players truly get the sense of ownership with their characters because they spend so much time on creating them that they become invested in who their character is (Turkay, 2013). This task however can be tedious for people, and in fact Lia's player said that they would prefer partial premade characters so they did not have to spend hours upon 
hours creating a character (Turkay, 2013). Lia's player stated that although they want to be able to customize their character they prefer to spend time playing the game as the character and less time creating the character.

I agree with Lia's player that nothing compares to playing the game, but I do like to customize my own character and build them out how I imagine them. Within video games I forget about who the character is if I do not spend time creating them. Much like Shaw's (2010) players stated, if I am given a premade character I focus on playing them and not who they are to build a connection to them. But, when I am given the ability to sit down and build out a character, to decide who I want them to be and make them look a certain way, which is when I truly find myself connecting to the character. This is why creating characters within Dungeons \& Dragons is gratifying to me. Customization to me, is the ability to build out someone you want to play and I prefer to customize my characters and build them out how I want them because it makes my experience of playing a customized one that I feel a part of.

All of the participants agreed that their true connection to their character came when they had been given choice in their character upon leveling up, changing their character's name, and in building the character's backstory. On top of that all participants indicated that by being given a premade character they spent the first gaming session, or two, just trying to figure out who their character was and what they could do, which put emphasis on the actions of the character rather than to connection. My participants preferred to customize their characters and were okay with being given a base but they wanted the ability to choose their skills and weapons and even to customize what their characters looked like. By customizing and building out the character all participants agreed that is where they felt their connection to their character grow. Customization 
is also seen as a creative outlet for players and Krusk's player indicated that when they build characters they like to go for the crazy options to both exercise their creativity and to play something that they would not be able to do in their everyday life. By being able to exercise their creativity Krusk's player builds connection to their character because they get to both customize something from scratch and be creative in that process.

When players are given creativity and customization, many players feel like they have the ability to build their own narrative inside a larger one (Harrigan, \& Wardrip-Fruin, 2007). When I play Dungeons \& Dragons I like to build my character out and customize them from the beginning. Knowing that I can pick and choose my skills and abilities and figure out my character from day one makes it easier for me to understand my character and role play them. Customization gives me the ability to build something up as I want so that when I get to play as my character I can feel a stronger connection to them as I have invested more time in the character (Wolfendale, 2007). My participants felt the same and even found themselves asking me from day one what creative control they had in their characters. And two of my participants made changes to their character right away. Fem's player changed the character's name from Miri to Fem because it allowed the player to feel more connected to the character by allowing them to create the character they wanted. Additionally Krusk's player changed Krusk's ability scores and some attack information making the character match what Krusk's player envisioned in their head.

Creativity is a large component of role-playing games so when premade characters get thrown into the mix, many feel like their creativity has been stifled (Chung, 2013). My participants pointed out that premade characters made it harder for them to get a hold of who the 
character was within the limited timeframe. Krusk's player even stated that premades are generally meant for a quick day event and players are not meant to feel a connection to them. Some of my participants believed that there is too much customization in the process of creating their character. Nonetheless they all agreed that they still wanted choice in character creation. This theme falls in line with the Goldilocks dilemma when, in the children's book, Goldilocks tried to find perfect amount of hard and soft when looking for a bed to sleep on. (Shirado, Fu, Fowler, Christakis, 2013). Research done by Selen Turkay (2013) found that there is a fine line between too much and too little choice within games. Turkay (2013) referred to too much choice as "choice overload" and discussed that players may feel overwhelmed by choices sometimes to the point that they may even decide not to make a choice and instead step away from the game. Lia's player felt this to be true since they preferred to play the game as opposed to spending time with too much choice.

Kline et al (2003) also talks about how there can be a fine line between what is too much and too little choice for players when it comes to player satisfaction. My participants felt the same, where sometimes character creation takes too long and requires too much, but sometimes there is not enough customization and they want more. Lia's player talked about this when they were discussing why they liked the idea of a premade character. Lia's player indicated that character creation in Dungeons \& Dragons can be a tedious task and can even take them hours to complete, which becomes frustrating. However Lia's player also agreed that they needed some choice in the process of character creation because, if they cannot make the character feel like a product of themselves, they cannot feel a connection to the character. This is in line with Kline (2003) as he discusses the need for game designers to build in choice so players can feel like they 
are a part of the experience, however too much choice can become redundant to the game. In the end Lia's player agreed that in order to feel a connection to their character they need the ability to customize the character, but if they are given too much or too little customization they become detached from the game (Turkay, 2013).

Another theme that appeared in the coding was that whenever players talked about character customization they were generally talking about why premade characters are bad. Below is the tree map of the coding in NVivo:

Nodes compared by number of coding references

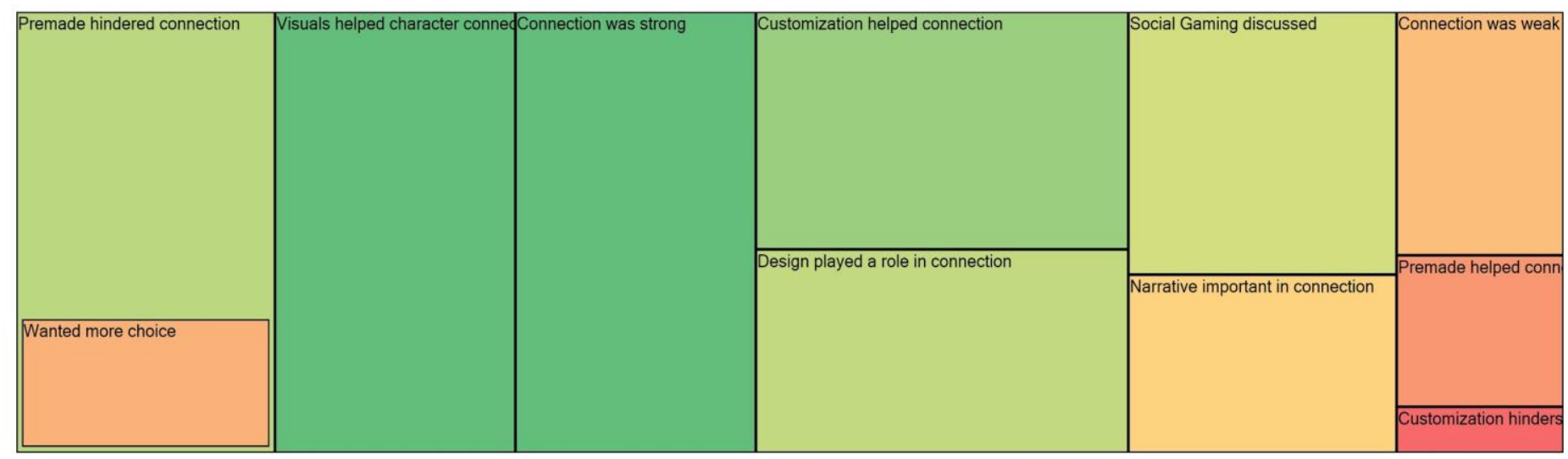

Figure 2.1 NVivo Tree Map displaying the nodes coded with NVivo where size indicates total amount of reference and colour indicates connection to other nodes.

This tree map shows node clusters in a visual way that outlines both the amount of reference per node and their connection to other nodes. The size of the section indicates how many times the specific reference was coded while the various colours represent their connection to the other nodes in the map with similar colours having more overlying references. For example, the two dark green sections (visuals helped connection and where connection was strong) represent both 
the amount of references within the coding data (represented by the size of the space) as well as the colour representing the strong connection to each other. Similarly the section titled customization helped connection is its own green which indicates that references had connection to both the dark green and the lighter green areas. This is important because it shows patterns in the player's references to their experience connecting to their avatars within the in-game research.

Premade characters can add a level of difficulty for any player no matter how experienced they may be (Shaw, 2010). When players are given premade characters they have to quickly adjust to the character and start playing it, which usually ends up with them focusing more on the character's actions and less on who they are (Shaw, 2010). This is also shown in the tree map (see Figure 2.1) indicated by the colour orange, that when participants discussed game design, they also discussed how experience in the game and mostly game mechanics played a role in their character connection. Both Lia and Fem's player agreed that when starting out with their premade character they focused on the actions and mechanics behind playing their character. Once they both got comfortable with the game mechanics they ended up experiencing a strong connection through role-playing their avatars. Lia and Fem were both less experienced players and they believed that their lack of experience affected their ability to connect.

Being given a premade character forces you to figure out every little detail as you go along. However, once players found themselves leveling up throughout the campaign and gaining experience, I could tell they were starting to get into character. All participants admitted that once they were able to customize their characters, and make choices, they were able to match it to their individual play style thus making it easier for them to identify with their 
character. However some still struggled with connecting to their character. A great example of challenges in character connection comes from Lia's player when discussing personality trains where they state that:

"One [challenge] that definitely stood out to me was the flaws of the character [since Lia overlooked] simple solutions in favour of more complicated ones. That [personality traits] was kind of weird because that's not how I usually do things, especially in gaming. [Usually] I want to just get to the point, move forward and not spend time running around doing things."

Lia's player indicates that if the character's personality does not match that of their normal play style it can be challenging to experience a connection with the character, which was confirmed by Shaw's (2010) research. Within Shaw's (2010) her players indicated that if the player's personality did not match the character then the player felt less connection to the character. Lia's player felt similar indicating that if they did not care, or could not mesh with the player properly they would not have felt a connection to them (Shaw, 2010). Additional research done by both Selen Turkay (2013) and Ching-I Tang (2010) also found similar conclusions where they both discuss how customization to match the player generally ended with the player feeling more immersed in gameplay.

Lia's player was not the only one to discuss this phenomenon, in fact all four players talked about how they either customized the character to match their play style or they felt that it already did. Boudreau (2007) discusses this when she talks about how players feel disconnects between a game and themselves which can hinder their ability to immerse themselves in the characters identity. Alston's player indicated that if they were given a character that did not 
match their traditional play style they would have experienced a lot more challenge in character connection because there would have been a disconnect between their play style and the play style of the character. Similarly Krusk's player felt that the ability scores that were given to them did not match the player and in order to feel like they understood the character Krusk's player had to change Krusk's ability scores. Krusk's player stated that by lowering Krusk's intelligene they were able to justify playing Krusk as less intelligent within the game because it matched. Lastly, Fem's player changed the play style of their character because the player is used to melee attacks and felt the premade character limited that for them. So Fem's player decided to customize the character to allow the character to attack more than once on each turn which allowed the player to feel more attached to the character. My players wanted customization to ensure that their character suited how they tend to play games and once they were allowed to change attributes they agreed that their connection grew stronger to their character. This coincided with the research done by Teng (2010) where it was found that when a player can customize the game experience to match them they can become immersed in the game and thus are more loyal to the game playing it for longer periods of time.

Customization gives players the ability to build a character that suits them while still being creative. Whether they play that character out as a hybrid identity of themselves or if they choose to create them separately from themselves, customization still creates a strong connection to one's avatar (Turkay, 2013; Shaw, 2010; Teng, 2010; Boudreau, 2007). When I asked my participants whether they prefer premade characters or customized characters, all four of them indicated they wanted customization so they could create the character how they saw them 
playing out as opposed to how someone else saw them. The participants wanted to customize not only their players and their skills but also how their players fit into the narrative of the game.

\section{Character Backstory}

Narrative has been strongly regarded as an important part to the gaming experience where players like to be given choice in how they can carry out the game (Kline, 2003). Dungeons \& Dragons is an interesting medium to study as the game requires players to both create a story within gameplay and also to create a personalized character story for themselves (Ewalt, 2013). For this study players were given the chance to write their own character's backstory or better known as the life story of the character.

Gaming narrative has never been important to me, especially the life story (or backstory) of the character as many video games give you a life story explaining why your character came to be are and where they are going (Wei, 2011). When I first starting playing Dungeons \& Dragons the backstory did not seem like an important part of the game because I had never thought about it before. The Dungeon Master in my campaign created my backstory for me and it has always been this secondary piece that I began to realize was actually important. Once I started paying attention to who my character was and where she came from I started to get a better understanding of my character, Zakia, and why she did what she did. When I realized the importance of narrative and the character backstory in connecting with Zakia I began to feel like I was making decisions she would have made and I better understood how to play her.

The backstory within Dungeons \& Dragons is meant to give an understanding to each character as their life story, explaining how the players all met and how their character fits into 
the story. Building out the backstory is one part to character customization within the game, however as a previous player of the game I never viewed this component as an integral part of the character. I always felt the stats and the main character sheet was what made the character, I was surprised to learn however, that the data from my participants suggested otherwise. This data confirms Shaw's (2010) findings that in-game narrative is important to players because it gave them something to connect to.

Players can feel a stronger connection to their character through the use of role-playing and story narrative (Moser, \& Fang, 2015). Additionally in role-playing games players tend to connect to how the character is played rather than how the character physically looks (Shaw, 2010). This study confirms Shaw's (2010) findings as participants were less interested in how their character looked and more in how they acted and where they fit into the game narrative. All of my participants stated that they did not pay attention to the physical characteristics of the character (see Appendix A) because they had created an idea of how the character was and did not care what they physically looked like.

Since I never originally found it important, and have never written my own character backstory before, I decided to allow my participants to write their own backstory and asked them about their experience afterwards. All four participants indicated that being given the ability to build their own backstory forced them to think about who their character was, thus building a connection to their avatar. A great example of this is when talking to Krusk's player and discussing backstory with them. Krusk's player had decided in order to successfully play an evil character, and not derail the campaign, they needed to play the character as less intelligent. They had decided the backstory had to represent that so instead of actually writing out a backstory 
Krusk's player drew something that resembled cave paintings trying to stay true to the character they were building in their mind. By truly figuring out Krusk's life story the player was able to understand the character better and thus play them in a way that would help the campaign and further the story as opposed to derail it.

Role-playing games generally require the player to get into character and to play as that character (making it more of a performance) and being able to build out the character and their backstory helps the players understand the player and become more like them (Wei, 2011). Wei (2011) discusses role-playing as a process of a player becoming an actor and that there is a difference between a character and the player who is playing as the character. When players roleplay and take on their character they tend to build a connection that is stronger because they are trying to actually be the player (Wei, 2011). Krusk's player stated that it would have been hard for them to connect to their character if the backstory was provided stating that "creating a backstory is kind of what connects me to a character to begin with." But narrative in Dungeons \& Dragons is not just created by one player, a large aspect of narrative in the game comes from playing with others.

\section{Social Narrative}

Dungeons \& Dragons is a game where people play as a team working towards one common goal. All of my participants indicated that the reason they like playing the tabletop, non-digital version, of Dungeons \& Dragons is because they get to play with friends, giving them a reason to get together and just have fun. This was also discussed in Ewalt's (2013) book where his group of players said that the game is a way to forget about the real world and just have fun with friends. Multiplayer games have been around since $3500 \mathrm{BC}$ with early games like 
chess where players got together and played against each other (Pearce, \& Artemesia, 2009). Naturally multiplayer games are competitive, however, when Dungeons \& Dragons came into the gaming world it introduced a new form of cooperative gaming where players got together, built characters, and played together to fight evil (Kline, 2003).

When I play games, I like to play with people. I find that other players help push you to be your best and to play the game together. However I also see that other players soon look at you for what skills you have. While playing Dungeons \& Dragons as Zakia my role is the rogue or the thief who is meant to pick locks, steal things, break into things, and generally be quiet and sneaky. I understand that and fall into that role, however the other players, although they make the game fun to play, constantly push me into that role even when I would prefer not to play it. I begin to feel like the other players view me as just this thief and use me to do everything they do not want to do because I can probably succeed at it. This frustrates me within any game and coincides with the discussion of roles within Boudreau (2007).

Players choose who their character is and how they fit into the story, but they then have to decide how all characters fit into the campaign together. The story often lends itself to a certain type of teamwork, suggesting some players will lead and others will follow along with what the group decides. This is discussed by Delanty (2003) when he talks about collectivities and roles within a community, talking about how people have specific roles in their community and they have to fulfil that role whether it is a small or large role. But in the end all of my participants felt connected to being able to work together on a common goal with each other. All of my participants agreed that their character connection grew while they played with the other participants. Even if there were instances where members were frustrated, the situation still made 
the player really consider how to work with their companions while figuring out who their character was within the mix. For example, Krusk's player talked very highly about social gaming stating that they would prefer to play whatever character is left in a group to round it out to ensure that their companions have the best gaming experience. This is shown within Ewalt (2013) when he discusses how social the game of Dungeons \& Dragons really is discussing both his companions and himself within gameplay and how the wrong person can impede the experience. When building a group to play with Ewalt (2013) discusses how one player can derail a campaign because they may feel they know everything and did not seem to care about the other players. Nevertheless the game itself is just meant to be an excuse to get together with friends and play a game.

Roles within a game like Dungeons \& Dragons can be complex, as discussed by Boudreau (2007), sometimes when you are the healer people just view you as that healer however you may feel like your character is more than that. By being stuck in a role you can get frustrated with the other players and with the game itself. Lia's player experienced this role frustration in the campaign as the player indicated to me that they felt like there were just being used for healing because they were the supporting healer. This is known as social norms within a game and many communities push players to abide by the social norms of their player and their community. By doing this, players may feel like they are there for one reason and have to fulfill that obligation as discussed by Boudreau (2007). Structures and roles within games can allow players to better understand their player within a community but they can also push a player into a stereotypical role that he or she may not want to be in. During the game Lia was pushed into the stereotypical healer role where they were expected to heal everyone when they needed it. 
Although Lia's player is used to being the supportive character, and thus built a connection to the character they did discuss how being the stereotypical healer frustrated them during play. The player started to feel like the other characters were forcing them to heal them and looked at the character as only a healer because that is what they were good for, but Lia's player felt the character was much more than just a healer thus being frustrated when players would push them into that stereotype. Lia's player grew an emotional connection to their character and would feel hurt when players just expected something from them as opposed to asking.

Playing in a community, although occasionally frustrating, also allows a player a greater ability to understand other players, especially when games are played in real life. Social gaming is a way to find out who you and your character is while having the ability to grow as a community as well (Turkay, 2013). When players build a narrative for their character they then have to intertwine that narrative with other players and try to make sense of why the characters all came together for the campaign. For example, in this research Alston and Krusk's players decided, when building their backstories, that their characters had met before and spent time together prior to meeting up with the group. In creating this narrative, the players built meaning into their characters and into the community they were building (Harrigan, \& Wardrip-Fruin, 2009). This in turn, helped them to connect with their characters and the other characters in the campaign (Harrigan, \& Wardrip-Fruin, 2009). Similarly, throughout this in-game research there were many instances where Alston's player would use the narrative freedom of the game to goof around with Krusk. This storyline helped to strengthen the sense of community in the group because it allowed both the two characters, and the people playing them to build a stronger relationship with each other. Players felt that narrative really helped them connect to their 
characters. Much like what Teng (2010) discussed in their literature, narrative allows players to become immersed in who the character is. On the other hand narrative is not enough for many players to truly build a connection to their avatar, some need a visual representation to be able to feel like their character (Boudreau, 2007). My research supported this idea as my players thought that narrative gave them an understanding of their character but felt that visuals helped guide their play thus creating a strong connection to their character during gameplay.

\section{Visuals in Character Connection}

Visuals in games became popular when digital video games came onto the market (Kline, 2003). But before video games, analog games had visuals through the use of tokens that would move around a game board much like the car in Monopoly or the pieces in chess (Pearce, Artemesia, 2009). The analog game Dungeons \& Dragons can be played with or without visuals, and this study incorporated both. The first two gaming sessions were played without visuals and the final two with a battle map and player tokens. Dungeons \& Dragons is meant to be a game full of exploration so instead of players being able to see traps they have to do something called a perception check, which allows them to look around and see if there are any traps around (Ewalt, 2013). A perception check is something a player has to actively choose to do, neither the game nor the Dungeon Master will tell them to do it thus making players think harder about how they play the game (Ewalt, 2013). This is different as compared to a visual game where players can see if there are traps or anything in their way that could potentially harm them.

I personally like visuals because they help me to understand where everything is in the game. When I play a video game like The Sims I know where the fridge is so when my Sim gets hungry I do not have to ask how far away I am from the fridge I can just see it and complete the 
action. However in a game like Dungeons \& Dragons, I have to ask where the location of the fridge is so I can figure out if my character has the ability to move there and eat food. This makes playing the game harder because I forget about checking for traps and wondering how far away I am from an enemy because in a video game I am used to the visual showing me. Turkle (1995) says it best when she explains that we have become accustomed to the virtual simulation and virtual worlds, relying on images not text. I rely on images and simulations to guide my play within games thus preferring visuals over text.

My participants pointed out that visuals allowed them to focus on the avatars and playing as a group of characters. Lia's player themselves agreed that visuals allowed them to better understand the other players because they felt everyone was now on the same page. For example, before visuals were introduced both Lia and Fem's player thought that Krusk was a tall ogre, but after seeing the visual of the player they had a better understanding of who Krusk was and it was easier for them to realize that Krusk was really five foot five (which is short for an orc). When visuals are added into the mix, players get a better sense of how each player represents themselves (Boudreau, 2007). This makes for a more cohesive gaming experience because players are not just thinking what the player looks like they can see it in front of them and focus on playing alongside the player (Turkay, 2013).

Sometimes, visuals helped with gameplay in a more pragmatic sense. Three of the participants indicated that they liked playing the game with visuals because they did not have to spend time figuring out mechanics of the game since they could see it in front of them (Babu, 2012). For example, Alston's player stated that "the less questions I have to ask the more I am able to just drop myself into this character" meaning that visuals allowed them to forget about 
how far an enemy was from them and just play their own character. This coincides with research done by James Babu (2012) talking about gaming interfaces and how the mechanics of the game, such as the players health and skills, need to fall into the background and yet be present enough for players to see it. Babu (2012) concludes that if the interface is done well enough players can become immersed in gameplay and forget about what to do and enjoy playing the game.

Visuals can also help players become immersed in the gaming world and entrenched in what they are doing (Babu, 2012). Within the NVivo coding data Fem's player had the most references to visuals within gameplay. Fem's player stated that visuals helped them play the game not only because they could see their character better but because they could understand the context to the game better. Fem's player admitted to growing up in the age of video games and talked a lot about how, because they grew up on video games, they are used to playing games with visuals. The visuals guide Fem's player in the game so they do not have to think about what to do next, they can see what they have to do next. Alston's player concurred with Fem saying that they did not need a lot of visuals but some kind of representation of the character helps them. Both players agreed that by adding in a visual component to a game they get to forget about a few things and just focus on the important parts to the game and not every minute detail (Babu, 2012). This then helped both of the players build a connection to their avatars and to their gaming companions because they were able to pay more attention to the character and less to the character's actions.

It is important to know that connection was built for players during both the non-visual and the visual aspects of the game, however many stated that by having the visuals placed in front of each player they were able to forget about the mechanics of the game and just see it in 
front of them. Fem's player said it best when they discussed the difference between video and analog games stating that:
"You can give a narration of a room and [tell me] what I see in the room and that's one thing, but if I can see the room...that makes it feel more like a world [to me], like it is a more cohesive [game]"

What Fem's player is saying is that in a video game they can look around the room and see if there are traps and what type of door it is, however in Dungeons \& Dragons you have to ask those questions which takes you out of the game and thus makes you spend less time connecting to your character. Ballsun-Stanton, \& Russell (2012) shows that when players can see things on a screen they do not have to worry about asking whether or not it is there. If you as a player already know what the walls look like, or who is in the room, through visual aids you do not have to think about asking and you can just focus on what your avatar is going to do (BallsunStanton, \& Russell, 2012). Boudreau (2007) discusses the connection between a player and their environment and how there is a disconnect in what the player knows and what the character knows. She discusses that a player may know what to do when faced with a trap but they have to create a connection between the player and characters action to ensure they disable the trap properly (Boudreau, 2007). Fem's player stated that they feel a disconnect between a visual environment and a text based environment mentioning that while they can see a trap in a video game, in Dungeons \& Dragons they have to actively remember to look for one. This extra step serves to create a disconnect between the gaming environment and the player (Boudreau, 2007). This is also discussed by Babu (2012) where it is pointed out that the overlay in video games needs to be present enough to be seen but not so prominent that it is in the way. If there is 
something in the way of a player's gaming experience there then becomes a disconnect between play and enjoyment thus making it harder to connect to one's avatars (Babu, 2012).

The last instance where visuals were seen as a positive was in the understanding of other players. One major theme that kept popping up in the study was that players were unable to visualize the character Krusk as the player sheet defined them. Players believed Krusk was a tall orc warrior at over six feet tall, however the character sheet had stated that Krusk was five foot five inches. This threw off the players because they were thinking Krusk was one way, yet without a visual they could not really picture the warrior. Similarly Alston's player mentioned that they were having difficulty grasping the fact that their own character was a tiny gnome. Alston's player had a hard time realizing the limitations of a four foot gnome and indicated that they were constantly forgetting that they were this tiny figure. Alston's player agreed that if they were able to see the character in a true visual they would have had an easier time visioning this tiny gnome and his limitations. Duchenaut et al, (2009) points out in their research that players tend to go for the player they wish they could be and that the experience of avatar personalization can be more about physical embodiment and less about exploring personality. Boudreau (2007) also discusses this when talking about how players want to feel different viewpoints within their gaming characters when some players who are six feet tall will play a three foot gnome to see life through their eyes. Without a visual, you would not know how tall a player truly is in comparison to you, but once you see that visually represented it is easy to see who is taller than who.

Lia indicated that an issue with having no visuals is that many players have an idea of what they look like and how they acted but that does not mean the other players shared the same 
views. Lia's player may have thought Krusk was a seven foot tall white orc barbarian but was confused when they were acting as a five foot green orc barbarian. Lia's player agreed that when the visuals were laid out in front of them they could better understand each player's actions so when Krusk did something evil it made more sense because Lia's player could look at Krusk's representation in visual form and have a better picture of the character completing the action. A lot of this is built in societal roles and ties into Boudreau's (2007) discussion of roles within community where she discusses the fact that one person may believe that you have to be a healer because you are a cleric but really you do much more than that. If you are able to visually see that a player has more than one skill you can understand them and connect with them in a stronger way than if you just have an idea in your mind of who they are (Turkay, 2013). The truth is that character connection is a complex experience but having visuals makes that experience a smoother process. Whether the participants found themselves connecting to customization, narrative, or visuals, all of my participants were able to connect to their character in their own way and feel like they were representing them well.

When it all came to a close, the players enjoyed their experience playing a premade character but they all agreed that next time they would want to be able to create their character from scratch. At the end of each interview players agreed that they prefer customization, building their own character backstory, social gaming, and visuals over being given something and being told to work with it.

\section{Conclusion}

Gamer identity can be built through many different means of play. Whether or not a player prefers analog or video games, it all boils down to motivations for play and one major 
motivation can be the character and how connected one can become with them (Teng, 2010). The character can be the means for a player immersing into the story where some players may favour the ability to see their avatars visually and customize them whereas others may prefer to customize out the backstory and game narrative.

Identity for any human is who they are and what they do and within the context of a game it is who their character is and what their character does within the story (Boudreau, 2007). Identity creation for this research was found to come from character creation and customization, gaming narrative both in building out the character backstory and through playing with other players, and through the use of visuals to help guide play. Players play games to feel like they are a part of something and giving them the ability to build identity allows them to take ownership of their experience and feel connected to both the game and their character.

\section{Limitations}

The study is limited in the sample size. As detailed in Janice M. Morse in Determining Sample Size (2000) a smaller sample size can provide data richness but is still limited in responses. Since the sample size is limited there cannot be any generalization statements made on how the gaming community as a whole feels about character identity within Dungeons \& Dragons. Furthermore, this research is not intended to represent a large portion of the gaming community as it is intended to be an exploratory study that can be used as a basis for future work. 


\section{Future Work}

Identity in video games has multiple applications into other aspects of gaming. This study can be conducted on the difference between music and no music, or done with a larger sample size. As well this study can be applied to other aspects of gaming and even gamification, taking players through different gaming experiences and seeing which players feel more motivated to complete. This study was limited in sample size thus any future work should use a larger sample size to incorporate more views and opinions from a larger group of gamers. 


\section{Appendix A - Dungeons \& Dragons Fifth Edition Character Sheet}
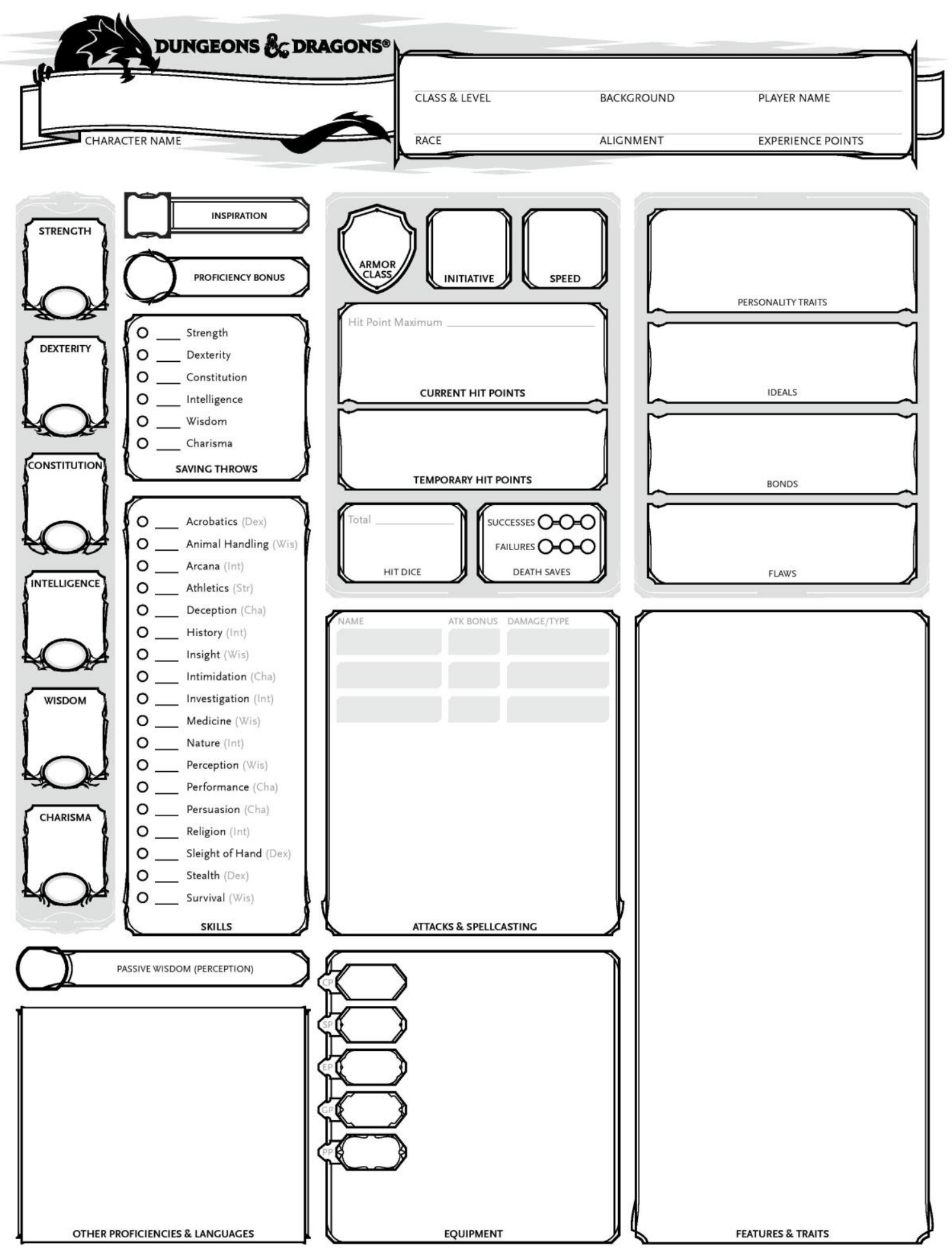


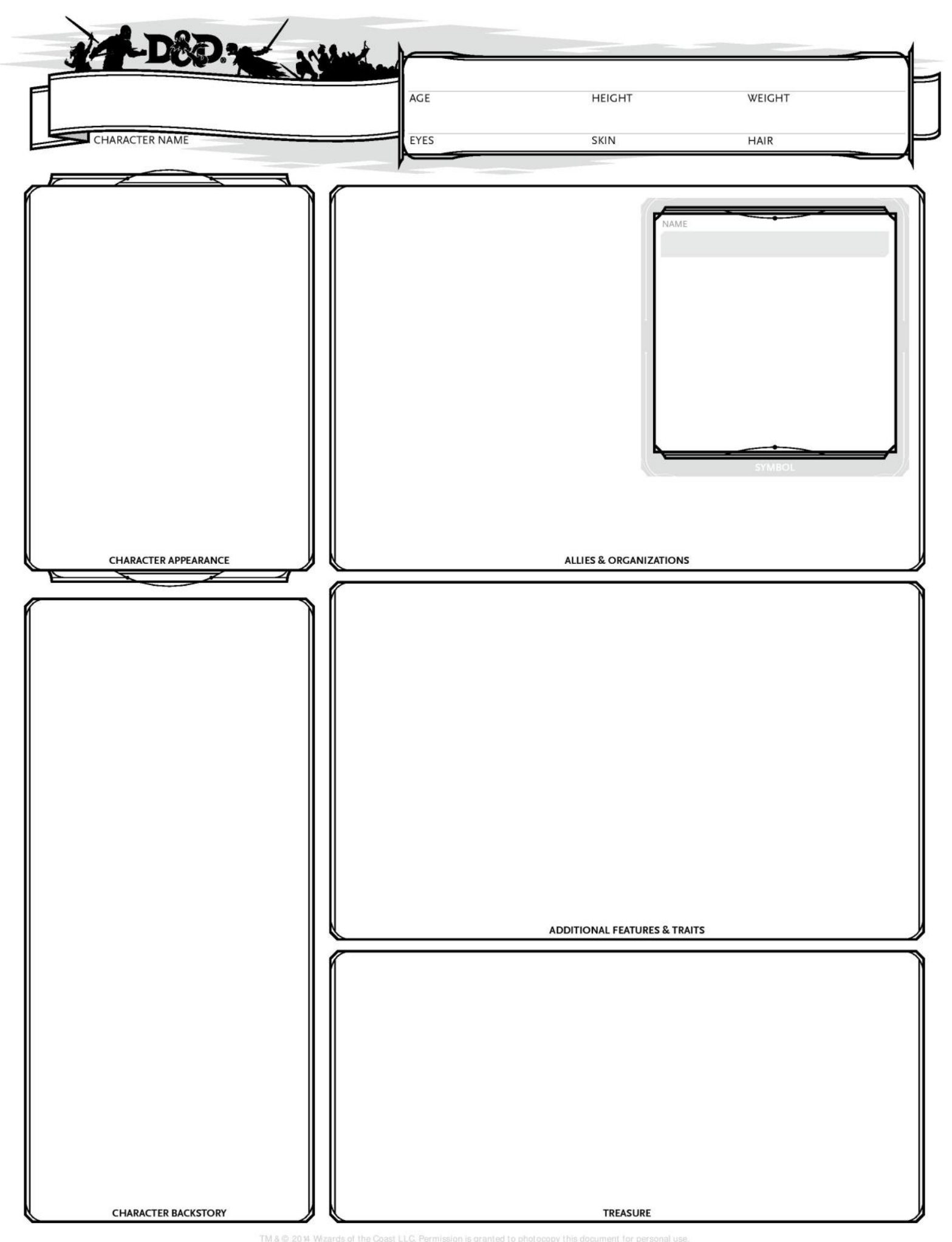



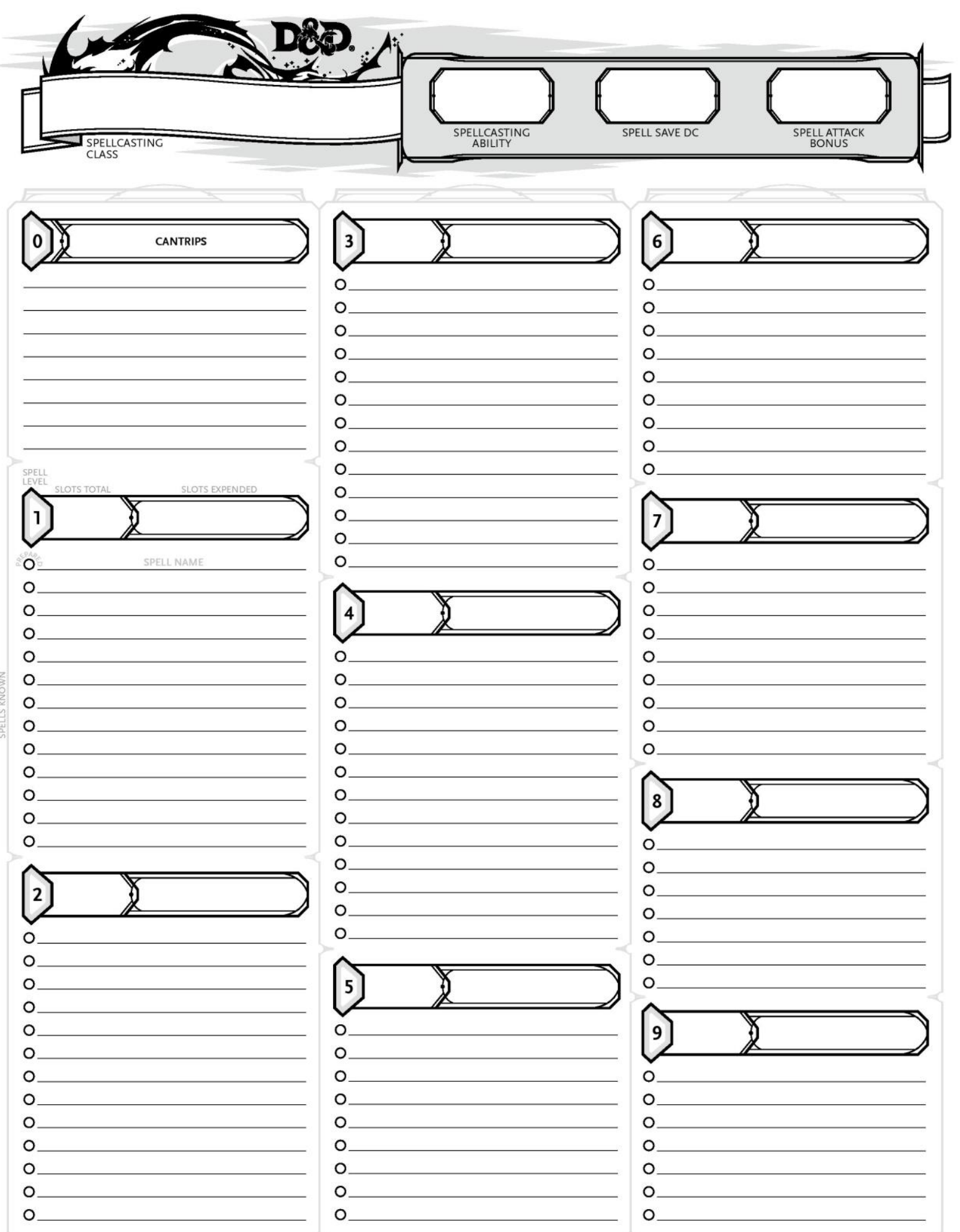


\section{Bibliography}

Babu, J. (2012). Video game HUDs: Information presentation and spatial immersion. ProQuest Dissertations \& Theses A\&I; ProQuest Dissertations \& Theses Global.

Baek, Y. (2013). Psychology of Gaming. Hauppauge, NY, USA: Nova Science Publishers, Inc..

Ballsun-Stanton, B., \& Russell, S., Constrained Optimization in Dungeons \& Dragons: A Theory of Requirements Generation for Effective Character Creation.

Banister, Peter, Bunn, Geoff, \& Burman, Erica. (2011). Qualitative Methods in Phycology: A Research Guide. Glasgow: Bell and Bain Ltd.

Boudreau, Kelly, (2007). Pixels, Parts \& Pieces: Constructing Digital Identity.

Bowman, S.L., (2010), The Functions of Role-Playing Games: How Participants Create Community, Solve Problems, and Explore Identity, Jefferson. USA: McFarland \& Company INC.

Braun, V., \& Clarke, V. (2006). Using thematic analysis in psychology. Qualitative research in psychology, 3(2), 77-101.

Chung, T. (2013). Table-top role playing game and creativity. Thinking Skills and Creativity, 56-71.

Delanty, G., (2003). Community London. UK: Routledge.

Denzin, N.K., (1997). Interpretive Ethnography: Ethnographic Practices for the 21st Century. Thousand Oaks, USA: Sage Publications

Ducheneaut, N., Wen, M.H.D., Yee, N., \& Wadley, G., (2009). Body and Mind: A Study of Avatar Personalization in Three Virtual Worlds.

Ewalt, D.M., (2013). Of Dice and Men: The Story of Dungeons \& Dragons and The People Who Play It. Scribner.

Harrigan, P., \& Wardrip-Fruin, N. (Eds.), (2007). Second Person: Role-Playing and Story in Games and Playable Media. Cambridge, Massachusetts, The MIT Press.

Harrigan, P., \& Wardrip-Fruin, N. (Eds.), (2009). Third Person: Authoring and Exploring Vast Narratives. Cambridge, Massachusetts, The MIT Press.

Jenkins, Richard, (2008). Social Identity, $3^{\text {rd }}$ edition. New York, New York: Routledge 
Kline, S., Dyer-Witheford, N., \& De Peuter, G., (2003). Digital Play: The Interaction of Technology, Culture, and Marketing. Montreal, QC, Canada; McGill-Queen's University Press.

Kwon, E., \& Back, K. J. (2009). A content analysis of gaming research: 1994-2008. Worldwide Hospitality and Tourism Themes, 1(4), 367-378.

LeBron, L. Procedural Character Generation for Narrative Games.

Li, D. D., Liau, A. K., \& Khoo, A. (2013). Player-Avatar identification in video gaming: Concept and measurement. Computers in Human Behavior, 29(1), 257-263.

Morse, J. (2000). Determining sample size. Qualitative Health Research, 10(1), 3-5.

Moser, C., \& Fang, X. (2015). Narrative structure and player experience in role-playing games. International Journal of Human-Computer Interaction, 31(2), 146-156

Pearce, C., \& Artemesia, (2009), Communities of Play: Emergent Cultures in Multiplayer Games and Virtual Worlds, Cambridge, Massachusetts, The MIT Press.

Shaw, Adrienne, (2010). Identity, Identification, and Media Representation in Video Gameplay: An audience reception study.

Shirado, H., Fu, F., Fowler, J. \& Christakis, N.A., (2013). Quality versus quantity of social ties in experimental cooperative networks. Nat. Commun.

Teng, C. (2010). Customization, immersion satisfaction, and online gamer loyalty. Computers in Human Behavior, 26(6), 1547-1554.

Turkay, S. (2013). The effects of customization on player experiences in an extended online social game: A mixed method study. ProQuest Dissertations \& Theses A\&I; ProQuest Dissertations \& Theses Global.

Turkle, S., (1995). Life on the Screen: Identity in the Age of the Internet. New York, USA: Simon \& Schuster Paperbacks.

Tse, E., Greenberg, S., Shen, C., \& Forlines, C. (2006). Multimodal Multiplayer Tabletop Gaming.

Waggoner, Z., (2009). My Avatar, My Self: Identity in Video Role-Playing Games. Jefferson, USA: McFarland \& Company INC.

Wei, H. (2011). Analyzing the game narrative: Structure and technique. ProQuest Dissertations \& Theses A\&I; ProQuest Dissertations \& Theses Global.

Wolfendale, J., (2007). My avatar, my self: Virtual harm and attachment. Ethics and Information Technology, 9, 111-119. 